\title{
Experimental Analysis of Stress Concentration on V-Notched Plate
}

\author{
Alka Sawale, Nayani Uday Ranjan Goud, M.Srinikitha
}

\begin{abstract}
Failure of notch occurs under the loading condition in the region where the stress distribution is disturbed. The proper study of effect of shapes and orientations of notches is imperative. The prediction of maximum stress developed at notches avoids such failures that ensure safe design of elements. The problem of stress-concentration effects, produced by holes and notches in plates under tension is, of interest to machine designers. Stress concentration is very important parameters to know where the stress is observed on object when it is subjected to different loading conditions. The evaluation of disturbances such as voids in on object increase the stresses approximately in the vicinity of discontinuity hence its effect must be accounted. In this project the experimental and FEM is applied out to find stress concentration factor considering an aluminium plate with $v$-notch and the final point where been similar with data.
\end{abstract}

Keywords: Stress concentration, stress concentration factor, $V$ notch, maximum stress

\section{INTRODUCTION}

Dramatic change were source from deformations in the destruction of stress known to be as stress focus, which were called as stress, bending in the form of holes, grooves etc., The flaws includes in the material on the surface or layers serve as stress rising.
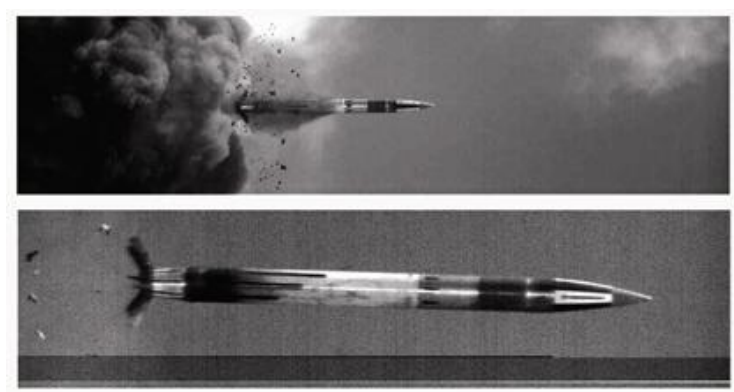

Fig1: Notch rectangular plate.

\section{LITERATURE}

The stress focus is a point on material where pressure is bombarded.

Revised Manuscript Received on December 30, 2019.

* Correspondence Author

Alka Sawale*, Assistant Professor, Department of Aeronautical Engineering MLR Institute of Technology, Dundigal, Hyderabad, Telangana, India

Nayani Uday Ranjan Goud Assistant Professor, Department of Aeronautical Engineering MLR Institute of Technology, Dundigal, Hyderabad, Telangana, India.

M.Srinikitha, Student, Department of Aeronautical Engineering, CMRTC,Hyderabad,Telangana,India.

(C) The Authors. Published by Blue Eyes Intelligence Engineering and Sciences Publication (BEIESP). This is an open access article under the CC-BY-NC-ND license http://creativecommons.org/licenses/by-nc-nd/4.0/
A product is stronger when pressure is equally spread over its surface, so a internal lines are formed, e.g., caused by a defect, results in a localized in stress as shown below figure 3 .

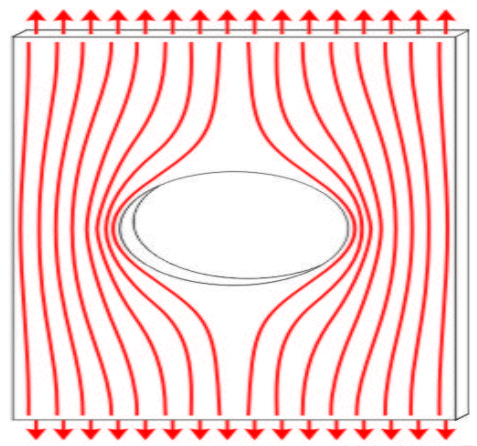

Fig 2: the Hole Lines which are thicker near defect The stress focus for rigid load can be find as the relation of the original maximum stress in the disturbed and the average stress, and is gained through the equation (2.1.1)

$$
\begin{aligned}
& \mathrm{K}=\frac{\frac{\text { Actwal maximum stress }}{\text { Average stress' }}}{\text { Axial force }} \\
& \sigma=\text { Cross section area }
\end{aligned}
$$

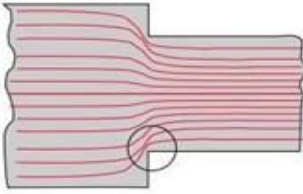

Abrupt change

Stress "flow lines" crowd

High stress concentration

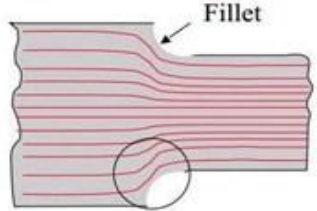

Smoother change

"Flow lines" less crowded Lower stress concentration
Fig3: showing high and lower stress locus

If the material is defect free and has no discontinuity, then the stress point factor is 1 . If there is great discontinuity, then the stress factor is $>1$.

\subsection{DETERMINATION OF $\mathrm{K}_{\mathrm{T}}$ VALUE:}

The stress factor consists of prescribed geometric and stressed condition on object which can be derived from various analysis and design methods

\subsection{FAILURE OF MATERIAL:}

Failure can be considered as component loses its capability to function as it is designed for. It can be failed in any aspects like corrosive, burn out, worn out, thermal stresses, magnetic stresses. Failure of material can cause lots of damage or losses to lives and the society

\section{FRACTURE}

The process of fracture divided in to two components, initial crack followed by crack propagation. 


\section{Experimental Analysis Of Stress Concentration On V-Notched Plate}

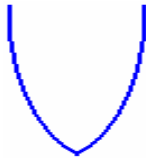

Rupture

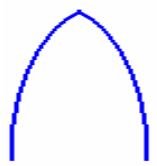

(a)

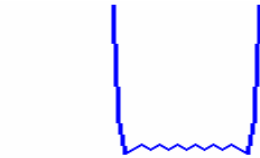

Cup-\&-Cone fracture

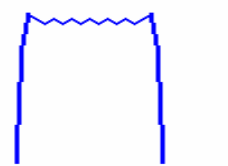

(b)

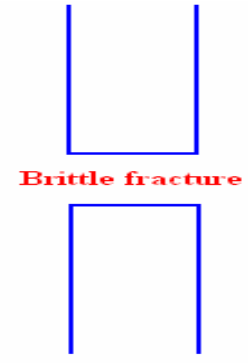

(c)
Fig4: Fracture profiles.

\section{EXPERIMENTAL SETUP}

\subsection{TEST MACHINE USED}

An Ultimate Testing Machine (UTM) used for the purpose of tensile test on aluminium $6061 \mathrm{HE}-20$ for determination of ultimate tensile strength and other parameters.

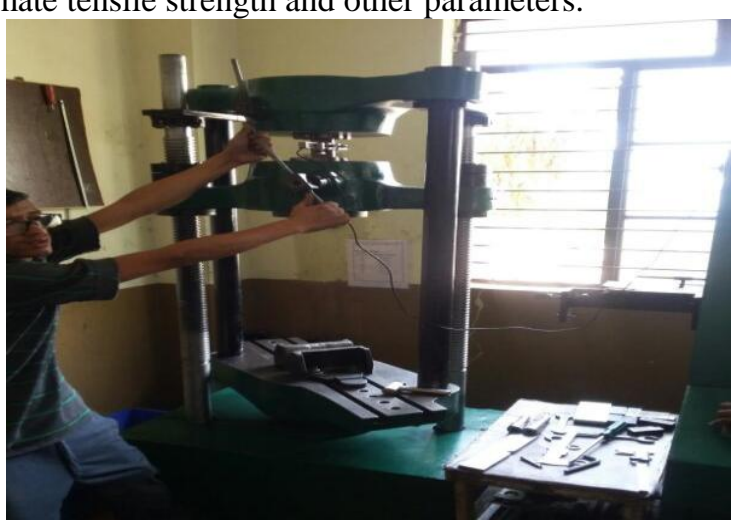

Fig 5: UTM setup

A UTM can also be known as universal tester i.e materials testing machine which is used to experiment compressive and tensile loads.

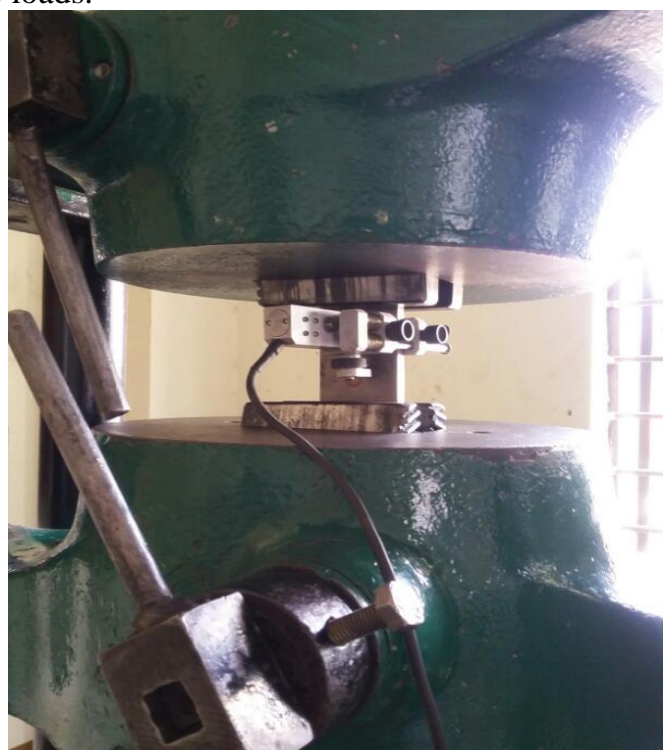

Fig 6: tensile testing on a specimen
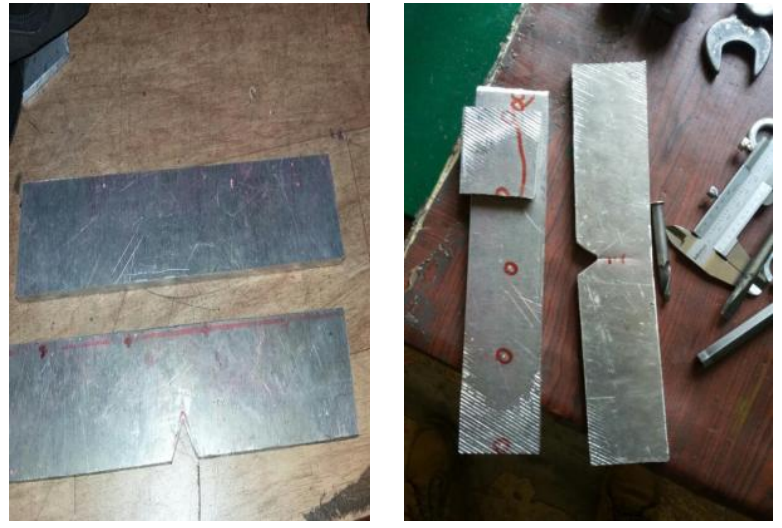

Fig7: Specimens before and after tensile test

\section{EXPERIMENTAL RESULTS}

By experimentally, Universal Testing machine (UTM) gives values on test specimen notched and un notched are given below:

TableI: Experimental results for unnotched and notched specimen

\begin{tabular}{|c|c|c|}
\hline & $\begin{array}{c}\text { UNNOTCHED } \\
\text { SPECIMEN }\end{array}$ & $\begin{array}{c}\text { NOTCHED } \\
\text { SPECIMEN }\end{array}$ \\
\hline $\begin{array}{c}\text { ULTIMATE } \\
\text { LOAD }\end{array}$ & $134.880 \mathrm{KN}$ & $44.600 \mathrm{KN}$ \\
\hline $\begin{array}{c}\text { ULTIMATE } \\
\text { TENSILE } \\
\text { STRENGTH }\end{array}$ & $330.167 \mathrm{~N} / \mathrm{mm}^{2}$ & $149.014 \mathrm{~N} / \mathrm{mm}^{2}$ \\
\hline YIELD LOAD & $111.440 \mathrm{KN}$ & $42.160 \mathrm{KN}$ \\
\hline YIELD & $272.970 \mathrm{~N} / \mathrm{mm}^{2}$ & $140.862 \mathrm{~N} / \mathrm{mm}^{2}$ \\
STRESS & & \\
\hline
\end{tabular}

$$
\mathrm{Kt}=\sigma_{\max } / \sigma_{\text {nom }}
$$

Calculating Kt value from experimental data: where

$$
\begin{aligned}
\sigma_{\max } & =149.014 \mathrm{~N} / \mathrm{mm}^{2} \\
\sigma_{\text {nom }} & =140.862 \mathrm{~N} / \mathrm{mm}^{2}
\end{aligned}
$$

\section{ANALYSIS OF PLATES}

For analysis we are using ANSYS workbench mechanical i.e., static structural and plates are designed in CATIA and those plates are imported into ANSYS and analysis is done.

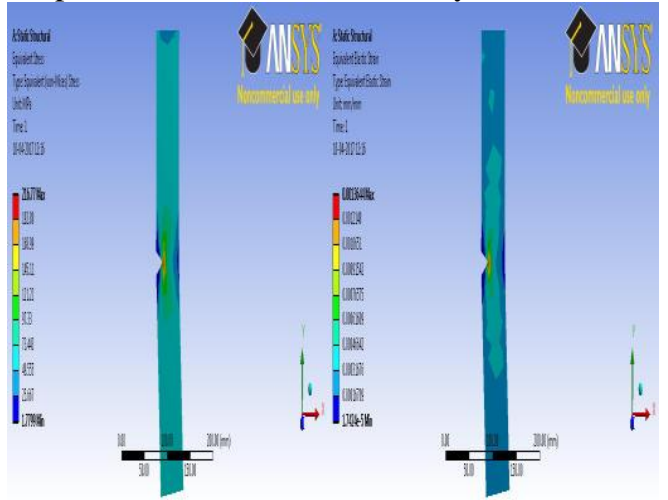

Fig 8: Equivalent stress and strain for notched plate 


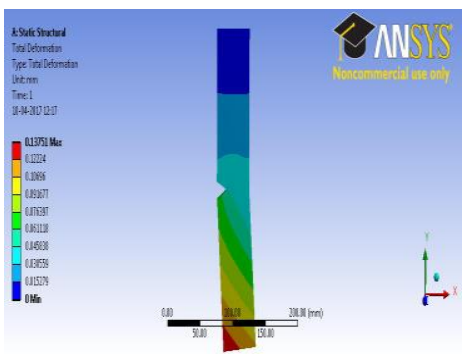

Fig9: Total defects for notched plate.

ANALYSIS FOR UNNOTCHED PLATE:

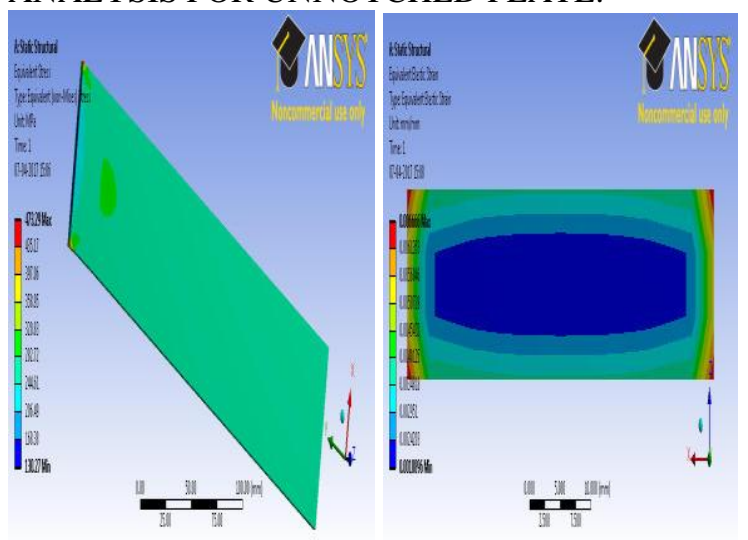

Fig10: stress and strain unnotched plate.

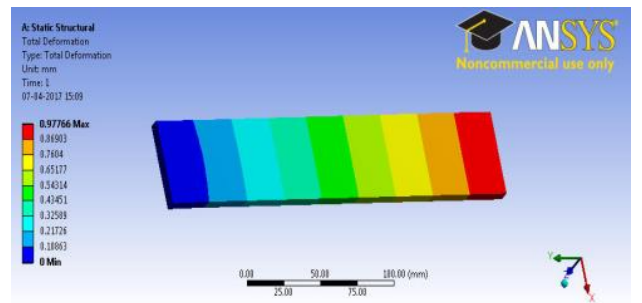

Fig11:Total deformation of unnotched plate.

\section{THEORITICAL CALCULATIONS}

\section{V-SHAPED NOTCH}

Fig.8 shows plate with single V Shaped notches. Dimensions for the notched plate are depicted in Table2. The different values of $C$ to be calculated for the range $\left(\frac{\mathrm{h}}{\mathrm{D}}\right)$ of ratio and $\alpha$ and $\mathrm{k}_{\text {tu }}$ values are depicted in Table 3

Table II: Dimensions for the V-shaped notched plate

\begin{tabular}{|c|c|}
\hline$H$ & $15 \mathrm{~mm}$ \\
\hline$D$ & $50 \mathrm{~mm}$ \\
\hline$D$ & $35 \mathrm{~mm}$ \\
\hline$A$ & $80^{\circ}$ \\
\hline$T$ & $8 \mathrm{~mm}$ \\
\hline$L$ & $250 \mathrm{~mm}$ \\
\hline$P$ & $\mathrm{P}^{*} \mathrm{D} * \mathrm{~h}$ \\
\hline $\mathrm{C}_{1}$ & -1.8788 \\
\hline $\mathrm{C}_{2}$ & 2.7072 \\
\hline $\mathrm{C}_{3}$ & 0.0086 \\
\hline
\end{tabular}

TableIII:Constants used in V-shaped notch.

\begin{tabular}{|c|c|c|}
\hline C VALUES & $\begin{array}{c}\left(\frac{\mathrm{h}}{\mathrm{D}}\right)=0.398,90^{\circ} \leq \mathrm{A} \leq \\
150^{\circ}, \\
1.6 \leq \mathrm{K}_{\mathrm{tu}} \leq 3.5\end{array}$ & $\begin{array}{c}\left(\frac{\mathrm{h}}{\mathrm{D}}\right)=0.667,60^{\circ} \leq \mathrm{A} \leq \\
150^{\circ}, \\
1.6 \leq \mathrm{K}_{\mathrm{tu}} \leq 2.8\end{array}$ \\
\hline $\mathrm{C}_{1}$ & $\begin{array}{l}5.294-0.1225 \mathrm{~A}+0.00 \\
0523 \alpha^{2}\end{array}$ & $\begin{array}{l}-10.01+0.1534 \mathrm{~A}-0.00 \\
0647 \alpha^{2}\end{array}$ \\
\hline $\mathrm{C}_{2}$ & $\begin{array}{l}-5.0002+0.1171 \mathrm{~A}-0 \\
000434 \alpha^{2}\end{array}$ & $\begin{array}{l}13.60-0.2140 \\
\mathrm{~A}+0.000973 \alpha^{2}\end{array}$ \\
\hline $\mathrm{C}_{3}$ & $\begin{array}{l}1.423-0.01197 \mathrm{~A}-0.0 \\
00004 \alpha^{2}\end{array}$ & $\begin{array}{l}-3.781+0.07873 \\
\mathrm{~A}-0.000392 \alpha^{2}\end{array}$ \\
\hline
\end{tabular}

$$
\begin{aligned}
& \mathrm{k}_{\mathrm{tu}}=1.472027 \\
& \mathrm{k}_{\mathrm{t}=} C_{1+} C_{2} \sqrt{\mathrm{k}_{\mathrm{tu}}}+C_{3} \mathrm{k}_{\mathrm{tu}} \\
& \mathrm{k}_{\mathrm{t}=1.4189} \\
& \sigma_{\text {nom }}=\frac{\mathrm{p}}{\mathrm{td}}=200 \mathrm{~N} / \mathrm{mm}^{2} \\
& \sigma_{\max }=\mathrm{k}_{\mathrm{t}} * \sigma_{\mathrm{nom}}=1.4189 * 200=283.78 \mathrm{~N} / \mathrm{mm}^{2}
\end{aligned}
$$

\section{RESULTS AND DISCUSSION}

A comprehensive summary and discussion of all conclusions drawn from this research study is provided within this section. From the experimental analysis of notches and un notched plates we have obtained the following results

TableIV: Experimental results

\begin{tabular}{|l|l|l|}
\hline & $\begin{array}{l}\text { UN NOTCHED } \\
\text { SPECIMEN }\end{array}$ & $\begin{array}{l}\text { NOTCHED } \\
\text { SPECIMEN }\end{array}$ \\
\hline $\begin{array}{l}\text { ULTIMATE } \\
\text { LOAD }\end{array}$ & $134.880 \mathrm{KN}$ & $44.600 \mathrm{KN}$ \\
\hline $\begin{array}{l}\text { ULTIMATE } \\
\text { TENSILE } \\
\text { STRENGTH }\end{array}$ & $330.167 \mathrm{~N} / \mathrm{mm}^{2}$ & $149.014 \mathrm{~N} / \mathrm{mm}^{2}$ \\
\hline $\begin{array}{l}\text { YIELD LOAD } \\
\text { YIELD }\end{array}$ & $111.440 \mathrm{KN}$ & $42.160 \mathrm{KN}$ \\
\hline STRESS & $272.970 \mathrm{~N} / \mathrm{mm}^{2}$ & $140.862 \mathrm{~N} / \mathrm{mm}^{2}$ \\
\hline
\end{tabular}

The ultimate load for un notched specimen is high than that for notched specimen also ultimate tensile strength, yield load and yield stress of un notched specimen are also found to have appreciable higher values than the notched specimen. It is viewed that radial point of notch has max significant on effective stress on the surface of the notch. Comparison stress concentration factor for experimental and theoretical analysis is shown below

\begin{tabular}{|c|c|c|}
\multicolumn{1}{|c}{ TableV : Stress concentrator values } \\
$\begin{array}{c}\text { STRESS } \\
\text { CONCENTRATION }\end{array}$ & EXPERIMENTAL & $\begin{array}{c}\text { THEORETIC } \\
\mathrm{AL}\end{array}$ \\
\cline { 2 - 3 } FACTOR & 1.058 & 1.4181 \\
\hline
\end{tabular}

Equivalent maximum stress values for experimental, theoretical and analytical are presented in below table:

\section{CALCULATIONS:- \\ $\mathrm{k}_{\mathrm{tu}}=3.065-8.871\left(\frac{\mathrm{h}}{\mathrm{D}}\right)+14.036\left(\frac{\mathrm{h}}{\mathrm{D}}\right)^{2}-7.219\left(\frac{\mathrm{h}}{\mathrm{D}}\right)^{3}$}




\section{Experimental Analysis Of Stress Concentration On V-Notched Plate}

TableVI: Equivalent maximum stress values

\begin{tabular}{|c|c|c|c|}
\hline $\begin{array}{c}\text { EQUIV } \\
\text { ALENT } \\
\text { MAXIM } \\
\text { UM }\end{array}$ & EXPERIM & ENTAL \\
\cline { 2 - 4 } STRESS & $\begin{array}{c}\text { THEO } \\
\text { RETIC } \\
\text { AL }\end{array}$ & ANALYTICAL \\
& $\begin{array}{c}149.01 \mathrm{~N} / \\
\mathrm{mm}^{2}\end{array}$ & $\begin{array}{c}200 \mathrm{~N} / \\
\mathrm{mm}^{2}\end{array}$ & $216.77 \mathrm{~N} / \mathrm{mm}^{2}$ \\
\end{tabular}

\section{CONCLUSION}

The values of stress concentration factor which are found in this report can be used for other types of plates with these design values. The relationship between v-notch stress focused factors, notch geometry, and final stress factors were mathematically modelled. The experimental relation providing the stress concentration factor as a function of the notch root radius was found to closely match with theoretical data. The experimental values of equivalent maximum stress were slightly differ from theoretical and analytical results due to geometric shape , material characteristics , voids \& inclusions present inside material. A formulation for the location of minimum equivalent stress within a smooth plate was developed and it was observed that this location acts as appoint of symmetry for stress distribution along the radius of the notch.

\section{REFERENCES}

1. Awerbuch, J., Madhukar, M. 1985. Notched Strength of composite laminates: predictions and experiments-A review. J. Reinf. Plast. Comp., 4: 3159.

2. Inglis, C. E. "Stresses in a Plate Due to the Presence of Cracks and Sharp Corners." Trans. Inst. Naval Architects, A221 (1913): 219-230.

3. Nathan.J.Mutter.,Stress concentration factors for V-notched plates under axisymmetric pressure-2010.

4. Santos. Determination of stress concentration factors on flat plates of structural steel -2013

5. Alka Sawale, MD Khaleel, S. Jaswanth "Design and Analysis of Winglet" International Journal of Civil Engineering \& Technology (IJCIET) May-17

6. M. Ganesh, K. Shiva Shankar. "Modeling and Analysis of Scaffolding Structure Used in Aerospace Vehicle" IJSR Volume 4 Issue 5 ISSN: (2319-7064)

7. Vamsi Krishna Chowduru, A Sai Kumar, "Numerical Investigation of Fluid Flows over a Rotor-Stator(Stage) in an Axial Flow Compressor Stage" IJERGS. Volume 3, Issue 4ISSN 2091-2730

8. Bhupal Rakham, Srinivas G . "Experimental and numerical analysis of convergent nozzle" Materials Science and Engineering. Jun-17

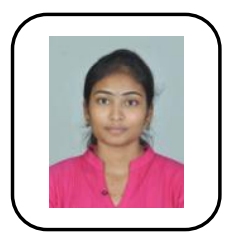

M.Srinikitha, Student Department of Aeronautical Engineering, CMRTC, Hyderabad, Telangana, India.

\section{AUTHORS PROFILE}

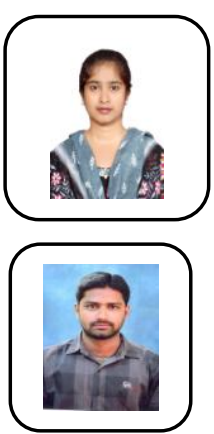

Alka Sawale, Assistant Professor, Department of Aeronautical Engineering MLR Institute of Technology, Dundigal, Hyderabad, Telangana, India, and her M.Tech in Aerospace Engineering . 